\title{
Nitric Oxide: Protein Tyrosine Phosphorylation and Protein $S$-Nitrosylation in Cancer
}

\author{
Hugo P. Monteiro ${ }^{1}$, Paulo E. Costa ${ }^{1}$, Adriana K. C. A. Reis ${ }^{2}$, Arnold Stern ${ }^{3}$
}

\begin{abstract}
Cancer is a worldwide health problem leading to a high incidence of morbidity and mortality. Malignant transformation can occur by expression of oncogenes, over-expression and deregulated activation of proto-oncogenes, and inactivation of tumor suppressor genes. These cellular actions occur through stimulation of oncogenic signaling pathways. Nitric oxide (NO) can induce genetic changes in cells and its intracellular generation can lead to tumor formation and progression. It can also promote anti-tumor activities. The pro- and anti-tumor activities of $\mathrm{NO}$ are dependent on its intracellular concentration, cell compartmentalization, and cell sensitivity. NO affects a number of oncogenic signaling pathways. This review focuses on two oncogenic signaling pathways: NO-EGFR-Src-FAK and NO-Ras-EGFR-ERK1/2 MAP kinases. In these pathways, low to intermediate concentrations of NO/S-nitrosothiols (RSNOs) stimulate oncogenic signaling, while high concentrations of NO/RSNO
\end{abstract} stimulate anti-oncogenic signaling. Increasing knowledge on pro- and

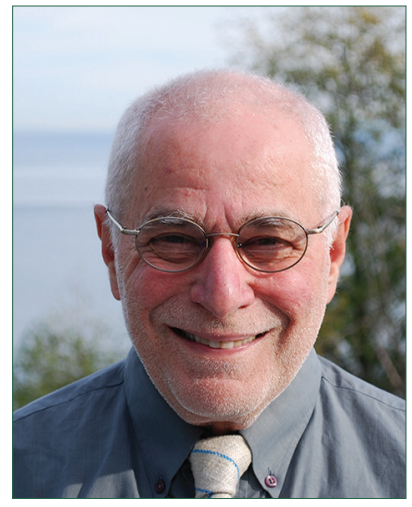

Dr. Arnold Stern anti-tumorigenic activities of NO and related reactive species such as RSNOs has fostered the research and synthesis of novel NO-based chemotherapeutic agents. RSNOs, effective as NO donors and trans-nitrosylating agents under appropriate conditions, may operate as potential chemotherapeutic agents. (Biomed J 2015;38:380-388)

\section{Key words: cancer biology, nitric oxide, protein phosphorylation, redox signaling, $S$-nitrosothiols, $S$-nitrosylation}

$\mathrm{N}$ itric oxide (NO) is a free radical with signaling capacity that plays an important role in the cardiovascular, neuronal, and immune systems, among others. NO regulates a number of physiological processes through the activation of two major signaling pathways: The activation of the enzyme guanylyl cyclase to form cGMP and $S$-nitrosylation, a covalent attachment of an NO moiety to a reactive cysteine residue in peptides and proteins. NO produced by the endothelial isoform of NO synthase (eNOS) regulates blood pressure. NO produced in neurons by the neuronal NOS isoform (nNOS) functions as a neurotransmitter. The constitutively expressed isoforms eNOS and nNOS release low fluxes of NO that are associated with cell protection and proliferation. Inflammatory cytokines and toxins induce the inducible NOS isoform (iNOS) in macrophages. Production of NO under these conditions is much higher compared to its production by constitutive enzymes. ${ }^{[1]}$ Higher NO fluxes such as those produced by iNOS stimulated by inflammatory cytokines in macrophages or generated by millimolar concentrations of $\mathrm{NO}$ donors are cytotoxic and promote

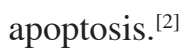

The constitutive NOS isoforms have been detected in some malignant tumors. Activation of eNOS is involved in the initiation and maintenance of tumor growth in pancreatic cancer cell lines. ${ }^{[3]}$ Tumor progression in prostate cancer is associated with eNOS expression, while malignant melanoma progression is associated with nNOS expression. ${ }^{[4,5]}$ The iNOS isoform is ubiquitously distributed in malignant tumors, but its role in tumor development is highly complex and poorly understood. ${ }^{[6]}$ The expression levels of iNOS and

From the ${ }^{1}$ Department of Biochemistry, Center for Cellular and Molecular Therapy- CTCMol, Escola Paulista de Medicina/Universidade Federal de São Paulo, SP, Brazil; ${ }^{2}$ Departament of de Ciências Exatase da Terra, Universidade Federal de São Paulo - Campus Diadema, Diadema, SP, Brazil; ${ }^{3}$ Department of Biochemistry and Molecular Pharmacology, New York University School of Medicine, New York, USA Received: Nov. 24, 2014; Accepted: Apr. 25, 2015

Correspondence to: Dr. Arnold Stern, Department of Biochemistry and Molecular Pharmacology, New York University School of Medicine, New York, USA. $4621^{\text {st }}$ Avenue, New York, NY 10016, USA. E-mail: arnold.stern@ nyumc.org

DOI: $10.4103 / 2319-4170.158624$ 
associated NO production in the tumor microenvironment may result in pro- or anti-tumor activities. High concentrations of NO produced by iNOS stimulated by inflammatory cytokines in macrophages often result in cytostatic and/or cytotoxic effects in tumor cells. ${ }^{[7]}$ Low concentrations of NO produced by constitutively expressed iNOS in tumor cells may cause tumor progression. ${ }^{[8]}$

The decomposition of specific compounds generally designated as NO donors serves as an alternative source for the generation of NO in physiological conditions. In addition to nitroglycerin (glyceryl trinitrate), the oldest and the most well-known NO donor, 16 different classes of nitrogen-oxygen-bonded compounds have the potential to decompose or be reduced/oxidized with the production of $\mathrm{NO}$ and other reactive nitrogen species. Structural differences among different $\mathrm{NO}$ donors lead to differences in the kinetics of NO release and reactivity. ${ }^{[9]}$

Clinical trials with glyceryl trinitrate to treat prostate cancer and preclinical trials with NO-donating non-steroidal anti-inflammatory drugs to treat colon cancer suggest that NO donors potentially could function as cancer chemotherapeutic agents. ${ }^{[10,11]}$ The role of $S$-nitrosothiols (RSNOs) as cancer chemotherapeutic agents in humans is yet to be explored.

\section{Nitric oxide and cancer: A two-way street}

A double-edged role for NO in cell biology has been proposed based on the local concentrations of the radical and on cell type susceptibility. ${ }^{[12]}$ The same concept has been applied to cancer cell biology, with NO displaying pro- and anti-tumor activities. ${ }^{[13]}$ NO-mediated biological effects are determined by its chemico-biological properties. $\mathrm{NO}$ is a gaseous free radical with signaling capacity. Living organisms ranging from bacteria to humans produce $\mathrm{NO} .{ }^{[14]}$ $\mathrm{NO}$ is a relatively stable free radical that neither dimerizes nor easily reacts with reducing or oxidizing compounds in biological systems. It is a selective reagent, which is an essential feature for a biological mediator, and weakly reacts with diamagnetic substances like the majority of organic molecules, but strongly reacts with paramagnetic substances such as transition metals (iron and copper), $\mathrm{O}_{\dot{2}}^{-}, \mathrm{O}_{2}$, and nitrogen oxides. ${ }^{[15]}$

The different mechanisms of NO signaling have been classified by Martinez-Ruiz and co-workers ${ }^{[16]}$ as classical, less classical, and non-classical. NO-mediated classical signaling involves nitrosylation of the regulatory ferrous heme of the soluble isoform of the enzyme guanylyl cyclase leading to its activation and increased production of the intracellular second messenger cGMP. High levels of cGMP in vascular smooth muscle cells cause vasodilatation. ${ }^{[17]}$

NO-mediated less classical signaling involves the interaction between $\mathrm{NO}$ and mitochondrial cytochrome $c$ oxidase.
Such interactions may be associated with the inhibition of mitochondrial oxidative phosphorylation, control of intrinsic apoptosis, and generation of reactive oxygen species. ${ }^{[16]}$

NO-mediated non-classical signaling involves modifications in tyrosine and cysteine residues of proteins. ${ }^{[16]}$ Nitration of protein tyrosine residues occurs by reaction with peroxynitrite $\left(\mathrm{ONOO}^{-}\right)$, a powerful oxidant generated at diffusion rates by the reaction of $\mathrm{NO}$ with $\mathrm{O}_{\dot{2}}^{-[18]}$ and by $\mathrm{NO}_{2}$ generated by neutrophil myeloperoxidase catalysis. ${ }^{[19]}$ Both oxidants nitrate tyrosine at position 3 of the phenolic ring, generating 3-nitrotyrosine. ${ }^{[20]}$ Tyrosine nitration may interfere directly or indirectly with tyrosine phosphorylation/dephosphorylation signaling pathways. NO derived from iNOS stimulation mediated tyrosine nitration of the epidermal growth factor receptor (EGFR), which caused a decrease in tyrosine phosphorylation levels and prevented neural stem cell proliferation. ${ }^{[2]}$ Cooperation or competition between tyrosine nitration and tyrosine phosphorylation has previously been discussed. ${ }^{[22]}$

$S$-glutathionylation refers to the incorporation of a GSH thiol group into a protein and the formation of a mixed disulfide bridge between a cysteine residue and the GSH thiol. It can be induced by $\mathrm{ONOO}^{-}$or formed after the reaction between a thiol and a nitrosothiol. $S$-glutathionylation has been classified as a non-classical NO-mediated signaling mechanism, but S-glutathionylation can be produced without the participation of $\mathrm{NO} \cdot{ }^{[16]}$

The reaction of $\mathrm{NO}$ with $\mathrm{O}_{2}$ (NO autoxidation) leads to the formation of $\mathrm{N}_{2} \mathrm{O}_{3}$. The same product is obtained after the reaction between $\mathrm{NO}$ and $\mathrm{NO}_{2}$. Lipophilic compartments like the cell membrane will concentrate $\mathrm{NO}$ and $\mathrm{O}_{2}$, two non-polar species, and facilitate the reaction between them, although these reactions are relatively slow. ${ }^{[23]}$ In aqueous systems, $\mathrm{N}_{2} \mathrm{O}_{3}$ in the presence of a nucleophile such as thiolate or an amine group will form a hybrid of covalent and ionic resonance structures $\mathrm{NO}^{+}-\mathrm{NO}_{2}^{-}$. Nitrosation reactions between $\mathrm{NO}^{+}$and the thiolate or between $\mathrm{NO}^{+}$and the amine form RSNO and nitrosamines, respectively. ${ }^{[23]}$ Although RSNOs are broadly classified as NO donors, their actions can also be exerted through trans-nitrosylation, without release of NO. ${ }^{[9]}$ Trans-nitrosylation is the exchange between a thiol group and a nitrosothiol group. Exchange may occur between a low-molecular-weight RSNO and a thiol group belonging to a peptide or protein without release of NO. Nitrosylating species of biological relevance, such as $S$-nitrosoglutathione (GSNO) and $S$-nitrosocysteine, can nitrosylate/trans-nitrosylate a number of signaling proteins. ${ }^{[24]}$

Protein $S$-nitrosylation ( $S$-nitrosation) is defined as the addition of a nitroso group moiety to a thiol group of a cysteine residue in peptides or proteins. Protein $S$-nitrosylation has been considered a mechanism for signal transduction by NO and RSNOs, ${ }^{[1]}$ and is not exclusively dependent on 
enzymatic activities as in the case with other post-translational modifications (PTM) such as phosphorylation. The nitrosylating agent's efficiency and the intracellular redox environment regulated by the redox couples oxidized glutathione/reduced glutathione (GSSG/2GSH) and oxidized thioredoxin/reduced thioredoxin (TrxSS/Trx) determine $S$-nitrosylation. ${ }^{[25]}$ Specificity of $S$-nitrosylation can be associated with the accumulation of high concentrations of nitrosylating species in the vicinity of specific cysteine residues in subcellular compartments. ${ }^{[26]}$ Another major aspect associated with the specificity of protein $S$-nitrosylation is related to the reactivity of certain cysteine residues located in determined nitrosylation motifs. Stamler and co-workers proposed that specific nitrosylation of cysteine residues occurs when flanked by acidic and basic residues within the protein primary sequence. ${ }^{[27]}$ This acid-base motif could explain reaction specificity by the stabilization of a thiolate as a more reactive form of the cysteine residue. The nitrosylation motifs have been defined as three-dimensional structures surrounding the cysteine residue. ${ }^{[24]}$ In these three-dimensional structures, the acid-base motif is located distantly to the cysteine residue and its charged groups are exposed. Exposure of the charged groups of the acid-base motif will facilitate trans-nitrosylation through protein-protein interactions.

Cross-talk by NO-mediated signaling events is associated with phosphorylation/dephosphorylation. ${ }^{[28-31]}$ The major focus of this review is on the role of protein $S$-nitrosylation and its interactions with protein phosphorylation in oncogenic and anti-oncogenic signaling pathways. Discussion of oncogenic signaling associated with the other modes of NO signaling can be found elsewhere. ${ }^{[32-34]}$

At least 1000 proteins modified by $S$-nitrosylation have been identified in mammalian cells. ${ }^{[35]}$ Physiological nitrosylation of signaling proteins is directly related to the proliferation of normal and cancer cells. ${ }^{[28-30]}$ Cancer is a major worldwide health problem, displaying high incidence rates in developed as well as developing countries. Epidemiological studies performed in 2012 revealed that 32.6 million people in the world were diagnosed with cancer. Within this population, $57 \%$ of the new cases, $65 \%$ of deaths, and $48 \%$ of the total diagnosed population were found in developing countries [WHO - International Agency for Research on Cancer (IARC), 2014]. Cancer is defined as a multifactorial process characterized by deregulation of tissue growth resulting from mutations of genes that regulate cell differentiation and proliferation. ${ }^{[36]}$ Malignant transformation may occur through the expression of new oncogenes, over-expression and deregulated activation of proto-oncogenes, or by the inactivation of tumor suppressor genes. Cell transformation follows the cumulative change in the expression levels of these genes. ${ }^{[37]} \mathrm{NO}$ induces some genetic changes and a direct relationship is observed between the intracellular generation of $\mathrm{NO}$ and tumor formation and progression. ${ }^{[13,38]} \mathrm{NO}$ is not restricted to pro-tumor effects, since NO can also promote anti-tumor actions..$^{[2,39,40]}$ Nitrosative stress conditions resulting from an activated immune response or exposure to high concentrations of nitrosylating agents lead to cancer cell death. ${ }^{[7,39]}$ Therefore, concentrations of $\mathrm{NO}$, time of exposure, and cell sensitivity to the radical determine the NO-mediated course of action in tumor cells. ${ }^{[13,41]}$

\section{Low to intermediate concentrations of $\mathrm{NO} /$ RSNO stimulate oncogenic signaling pathways}

\section{The signaling pathway: NO-EGFR-Src-FAK}

Over-expression of the oncoproteins Src and FAK cytoplasmic tyrosine kinases and EGFR receptor tyrosine kinase was associated with colon, pancreatic, and breast cancer development. ${ }^{[37]}$ Expression of NOS isoforms was observed in these carcinomas, suggesting an important interaction between $\mathrm{NO}$ and the oncoproteins in the signaling pathways associated with tumor progression.

NO-stimulated tyrosine phosphorylation occurred in a set of proteins identified as part of the EGFR signaling pathway. ${ }^{[42]}$ The cytoplasmic protein tyrosine kinases FAK and Src, and the ERK1/2 MAP kinases had their phosphorylation levels increased in murine fibroblasts exposed to the NO donors, sodium nitroprusside (SNP) and $S$-nitroso- $N$-acetylpenicillamine (SNAP). ${ }^{[43]}$ These observations were corroborated by experiments in breast cancer cells incubated with the NO donor (z)-1-[2-(2-aminoethyl)- $N$-(2-ammonio-ethyl) amino] diazen-1-ium-1,2-diolate (DETA/NO) which showed that $s$-nitrosylation and tyrosine phosphorylation of EGFR and Src kinase activated oncogenic signaling pathways that included c-Myc, Akt, $\beta$-catenin, and the loss of PP2A tumor suppressor activity. ${ }^{[28]}$

Tyrosine phosphorylation and $S$-nitrosylation of $\beta$-catenin is related to tumor progression. Activation of $\mathrm{Src}$ in endothelial cells phosphorylated $\beta$-catenin on Tyr654, while eNOS-derived NO nitrosylated $\beta$-catenin on Cys619, leading to dissociation of $\beta$-catenin from its partner VE-cadherin in adheren junctions. Disassembled adheren junctions are associated with increased permeability in endothelial cells and loss of cell-to-cell contacts in transformed cells. ${ }^{[4,45]}$

Integrated proliferative and adhesive signals are important for enhanced survival of cancer cells. ${ }^{[46]}$ Activation of Src kinase involved conformational changes that allow the protein to interact and associate with FAK. ${ }^{[46]}$ FAK integrated the EGFR and other growth factor receptor-mediated signals with signals from integrin-mediated adhesion processes. NO-mediated association between Src and FAK was detected in murine fibroblasts exposed to increasing concentrations of SNP. ${ }^{[31]}$ 
In addition to Src and FAK, the other focal adhesion proteins, $\mathrm{p} 130 \mathrm{Cas}$ and protein tyrosine phosphatase $\alpha(\mathrm{PTP} \alpha)$, are important for survival signaling in cancer cells. ${ }^{[47]}$ Expression of PTP $\alpha$ in murine embryo fibroblasts (MEF) was related to low expression levels of iNOS, low levels of intracellular NO, and a reducing intracellular redox environment. ${ }^{[31]}$ In PTP $\alpha$-null MEFs, there were high expression levels of iNOS, high levels of intracellular NO, and an oxidizing intracellular redox environment. $\mathrm{NO} /$ RSNO-mediated signaling pathways involving the participation of Src, FAK, p130Cas, and PTP $\alpha$ in MEF were dependent on PTP $\alpha$ expression levels. ${ }^{[31]}$ Malignancy levels in different tumor cells could be related to these findings. In the A431 human epithelial carcinoma cells, the absence of PTP $\alpha$ was accompanied by high expression levels of Src and the EGFR, high intracellular NO levels, and high malignancy. ${ }^{[47,48]}$ Human estrogen-responsive breast cancer cells positive for PTP $\alpha$, had low intracellular NO levels and low proliferative and metastatic rates. ${ }^{[49,50]} \beta$-estradiol induced eNOS expression and NO production in MCF-7-PTP $\alpha$ null breast cancer cells. NO derived from $\beta$-estradiol stimulation of MCF-7 cells activated Src through Cys498 $S$-nitrosylation and phosphorylation of Tyr416. NO-mediated activation of Src in these cells was related to enhancement of cell invasion and metastasis. ${ }^{[51]}$

Although PTP $\alpha$ expression was correlated with low malignancy and absence of its expression was correlated with high levels of malignancy in estrogen non-responsive breast cancer cells, ablation of PTP $\alpha$ expression was associated with tumor regression. ${ }^{[52]}$

Despite the expression levels of PTP $\alpha$, the determining signaling events in NO-mediated tumor progression depend on $S$-nitrosylation and tyrosine phosphorylation of Src kinase, which is associated with the regulation of other focal adhesion proteins.

\section{The signaling pathway: NO-Ras-EGFR-ERK1/2 MAP kinases}

The Ras family of small GTPases, comprising the isoforms K-Ras, N-Ras, and H-Ras, act as a molecular switch in signaling pathways, switching from an inactive GDP-associated form to an active GTP-associated form. Conformational changes at the nucleotide-binding pocket of Ras take place when nucleotide exchange is operative. No covalent modifications arise from the GDP-GTP exchange. Covalent PTM modifications of Ras proteins determine its location in various intracellular compartments, and in some cases, the modifications promote GDP-GTP exchange. ${ }^{[33]}$ Ras farnesylation is a constitutive and irreversible Ras PTM, whereas reversible palmitoylation is essential for the trafficking of Ras isoforms from endomembranes to the plasma membrane. ${ }^{[44,55]}$ Conditional PTMs of Ras in- clude phosphorylation, ubiquitylation, glucosylation, and $S$-nitrosylation. ${ }^{[53]} S$-nitrosylation of Cys118, a conserved cysteine residue that is part of the NKCD sequence located at the guanine nucleotide binding pocket, is essential for NO/RSNO-mediated activation of Ras. ${ }^{[56,57]}$

Ras isoforms are mutated to encode constitutively active, GTP-bound oncoproteins in approximately $25 \%$ of all human cancers. ${ }^{[37]}$ In addition, a signaling pathway operative in normal as well as in cancer cells involves growth factor receptor tyrosine kinases, Ras, downstream protein kinases (e.g. Raf, MEK, and ERK1/2 MAP kinases), and transcription factors (e.g. Elk-1). ${ }^{[37]}$

Ras $S$-nitrosylation in rabbit aortic endothelial cells is transduced into a downstream cascade of phosphorylation events associated with the Raf/MEK/ERK1/2 MAP kinases signaling pathway ${ }^{[58]}$ In these cells, NO/RSNO-mediated activation of Ras is connected to the EGFR-initiated signaling. ERK1/2 MAP kinases activated through the Ras signaling cascade triggered by low concentrations of SNAP promote the trans-activation of the EGFR. ${ }^{[59]}$

Human umbilical vein endothelial cells stimulated with bradykinin (BK) caused stimulation of eNOS to produce NO, which then activated the Ras signaling pathway, leading to an ERK1/2 MAP kinases-dependent phosphorylation of a consensus sequence containing a Thr residue, followed by a Pro residue in the cytoplasmic domain of the EGFR. BK-stimulated tyrosine phosphorylation and cysteine $S$-nitrosylation of the EGFR with both PTMs conferred stability to the EGFR and allowed sustained signaling. ${ }^{[30]}$

Activation of the Ras-ERK1/2 signaling axis by RSNO/NO was strongly inhibited in different cell types stably over-expressing $\mathrm{Ras}^{\mathrm{C} 118 \mathrm{~S}}$, a non-nitrosatable form of Ras. ${ }^{[30,58,60]}$

Our early findings indicated that the Ras-ERK1/2 MAP kinases signaling axis in rabbit aortic endothelial cells was activated upon $S$-nitrosylation of Ras induced by low concentrations of RSNO/NO. Downstream to Ras, the ERK1/2 MAP kinases were phosphorylated and migrated to the nucleus, stimulating phosphorylation of Elk1. ${ }^{[58]}$ ERK-mediated transcriptional events influenced cell cycle elements, for example, induction of cyclin D1 expression levels. ${ }^{[61,62]}$ Enhanced synthesis of cyclin D1 and stimulation of the cyclin-dependent kinases CDK4 and CDK6 promoted phosphorylation of the nuclear oncoprotein $\mathrm{Rb}$ and its dissociation from the E2F family of transcription factors. Induction of cyclin $\mathrm{E}$ and $\mathrm{A}$ expression led to cell cycle progression. These findings indicate that low concentrations of RSNO/NO $S$-nitrosylate Ras, leading to activation of the downstream signaling cascade Raf/MEK/ ERK1/2 MAP kinases followed by cell cycle progression and proliferation. ${ }^{[58]}$

Activation of the Ras signaling pathway by low concentrations of GSNO in HeLa human cervical cancer cells 
led to cell proliferation. ${ }^{[29]}$ GSNO-stimulated activation of Ras and proliferation was not observed in HeLa cells over-expressing $\operatorname{Ras}^{\mathrm{C} 118 \mathrm{~S}}$. GSNO initially mediated activation of Ras at the plasma membrane; in a later stage, activation of Ras at the Golgi apparatus was observed. Inhibition of Src kinase prevented GSNO-mediated Ras activation at the Golgi and cell proliferation. ${ }^{[29]}$

The importance of $S$-nitrosylation of Ras ${ }^{\mathrm{C} 118}$ in mouse models of cancer development was illustrated by knocking down the expression of eNOS or over-expressing Ras ${ }^{\mathrm{C} 118 \mathrm{~S}}$, which decreased the levels of $S$-nitrosylated and active Ras as well as xenograft tumor growth in pancreatic cancer cell lines $^{[3]}$ and with a K-Ras point mutation at Cys118 that showed decreased tumorigenesis. ${ }^{[63]}$

Intermediate concentrations of the RSNO, SNAP, stimulated a Ras-dependent survival signaling pathway in HeLa cells with the participation of Trx. ${ }^{[64]}$ Trx migrates to the nuclear compartment in cells exposed to SNAP. This was associated with Akt phosphorylation and cell survival. ${ }^{[65]}$ In HeLa cells over-expressing Ras ${ }^{\mathrm{C} 118 \mathrm{~S}}$, Trx nuclear migration was partially prevented. Inhibition of Ras with the selective farnesyl transferase inhibitor FPTIII prevented Trx nuclear migration and promoted cell death. Downstream to Ras, the ERK1/2 MAP kinases were phosphorylated and activated concomitantly with Trx nuclear migration induced by SNAP. ${ }^{[64]}$

Treatment of HeLa cells with GSNO resulted in activation of caspase-3 and cell death. Over-expression of Trx is frequently found in malignant tumors with a poor prognosis. ${ }^{[66]}$ In HeLa cells with over-expressed Trx, activation of caspase-3 was prevented and cell viability was enhanced after treatment with GSNO. ${ }^{[67]}$

SNAP-mediated activation and migration of the ERK1/2 MAP kinases down-regulated the expression levels of the physiological inhibitor of Trx, Trx interacting protein (Txnip). Changes in Trx cellular compartmentalization under nitrosative stress conditions were dependent on the expression levels of Txnip, which are regulated by activation and cellular compartmentalization of the ERK1/2 MAP kinases. ${ }^{[6]}$ Down-regulation of Txnip expression in A549 lung cancer cells was associated with the epithelial-mesenchymal transition. ${ }^{[68]}$ Therefore, a survival-signaling pathway activated by nitrosative stress conditions negatively regulates Txnip expression levels and permits Trx nuclear migration and stimulation of cell survival. Trx nuclear migration in cancer cells is associated with increased cell survival, tumor development, and metastasis ${ }^{[69]}$ A general scheme illustrating the NO/RSNO-stimulated proliferative and survival signaling pathways operative in tumor cells is shown in Figure 1.

\section{High concentrations of NO/RSNO stimulate anti-oncogenic signaling pathways}

A "double-edged sword" character in cell biology has been attributed to NO. ${ }^{[9]}$ This character was later extended to cancer cells as the role of $\mathrm{NO}$ as a mediator of the cancer phenotype became apparent. ${ }^{[13]}$ Tumoricidal effects have been consistently associated with intracellular nitrosative stress conditions. Intracellular nitrosative stress conditions resulted from the combination of high $\mathrm{NO}$ concentrations with other reactive nitrogen species including $\mathrm{ONOO}^{-} .{ }^{[70]}$ Inhibition of Akt leading to compromised cell survival has been associated with high concentrations of $\mathrm{NO} / \mathrm{ONOO}^{-}{ }^{-[1]}$ Pro-inflammatory cytokines such as interferon- $\gamma$ and tumor necrosis factor (TNF)- $\alpha$ stimulated iNOS in macrophages to produce high concentrations of $\mathrm{NO}$ and of $\mathrm{ONOO}^{-}$, promoting tumor cell death. ${ }^{[7,70]}$ Sustained overproduction of $\mathrm{NO}$ is a pro-apoptotic modulator, activating caspases through the release of cytochrome $c$ from mitochondria into the cytosol, up-regulation of $\mathrm{p} 53$, and down-regulation of the anti-apoptotic protein Bcl-2..$^{[72]} \mathrm{NO}$-derived tumoricidal action can occur by exposing different cancer cell types to high concentrations of exogenous NO donors. ${ }^{[2,11,72]}$

MDA-MB-231 breast cancer cells and DU145 prostate cancer cells exposed to millimolar concentrations of DETA/NO underwent apoptosis. ${ }^{[73,74]}$ Apoptosis was related to DETA/NO-induced $S$-nitrosylation of p53 and glyceraldehyde 3-phosphate dehydrogenase (GAPDH) in both tumor cell lines. ${ }^{[75,76]}$ These findings illustrate the importance of $S$-nitrosylation in signaling pathways associated with the induction of apoptosis in cancer cells.

The anti-adhesive properties of NO demonstrated in the inhibition of platelet aggregation ${ }^{[77]}$ were related to its action on the proteins belonging to the focal adhesion complex resulting in cell death. ${ }^{[78]}$ The anti-adhesive properties

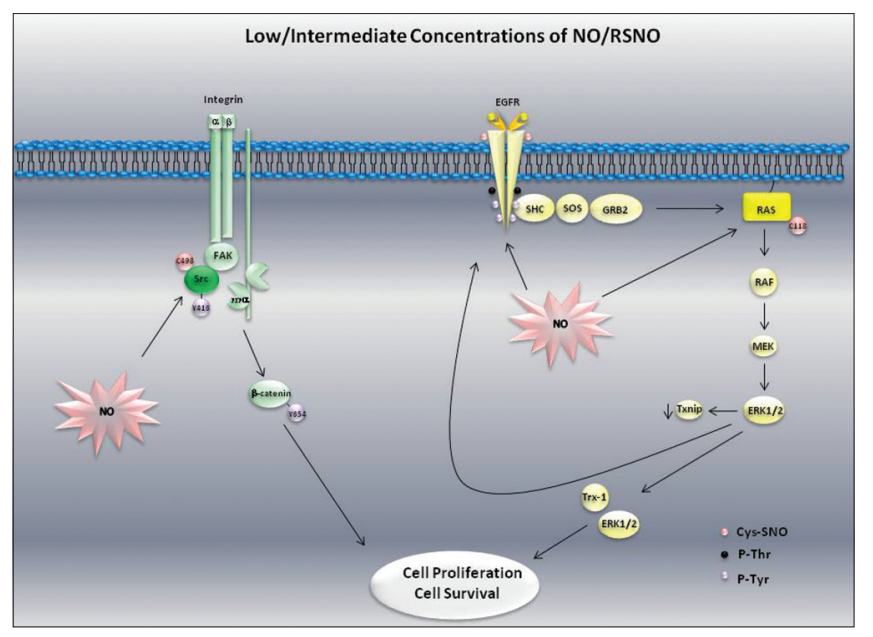

Figure 1: NO/RSNO-stimulated proliferative and survival signaling pathways operative in tumor cells. 
of NO include inhibition of cell adhesion and disruption of the interaction between the cell and the extracellular matrix. Its anti-adhesive properties place $\mathrm{NO}$ as a potential cause of cell death induced by detachment from a growth permissive surface ("anoikis"). ${ }^{[78]}$ Cell detachment and induction of a caspase-8/caspase-3 apoptotic signaling pathway was observed in A431 human vulvar cancer cells that express negligible levels of the phosphatase PTP $\alpha$, after treatment with SNP. Exposure of A431 cells over-expressing PTP $\alpha$ to SNP decreased the activation of caspase- 8 and caspase-3 and induced cell death predominantly by necrosis. ${ }^{[39]}$

Different concentrations of the RSNOs lead to different outcomes derived from upstream $S$-nitrosylation of Ras. ${ }^{[30,58,60]}$ This is supported by findings on the induction of the apoptotic process in human acute monocytic leukemia cells (THP-1) through the activation of the Ras-ERK1/2 MAP kinases pathway by high/supra-physiological concentrations of GSNO. GSNO-mediated $S$-nitrosylation of Ras was followed by stimulation of phosphorylation of the ERK1/2 MAP kinases and up-regulation of the cell cycle inhibitor $\mathrm{p} 21^{\text {Waa }}{ }^{[60]} \mathrm{Up}$-regulation of $\mathrm{p} 21^{\text {Waf }}$ levels leads to the trans-activation of $\mathrm{p} 53$ which promotes cell cycle arrest at the G1-S phase transition, ultimately leading to apoptotic cell death. ${ }^{[79]}$ Therefore, the Ras-ERK1/2 MAP kinases pathway may function as a sensor of the intracellular levels of RSNO/NO, signaling to cell proliferation or to cell death, according to these levels.

A general scheme illustrating the NO/RSNO-stimulated anti-proliferative/pro-apoptotic signaling pathways in tumor cells is shown in Figure 2.

\section{Potential role of NO donating compounds as tumoricidal agents}

The chemical diversity of NO donors shows promise as chemotherapeutic agents. NO donors have varying half-lives

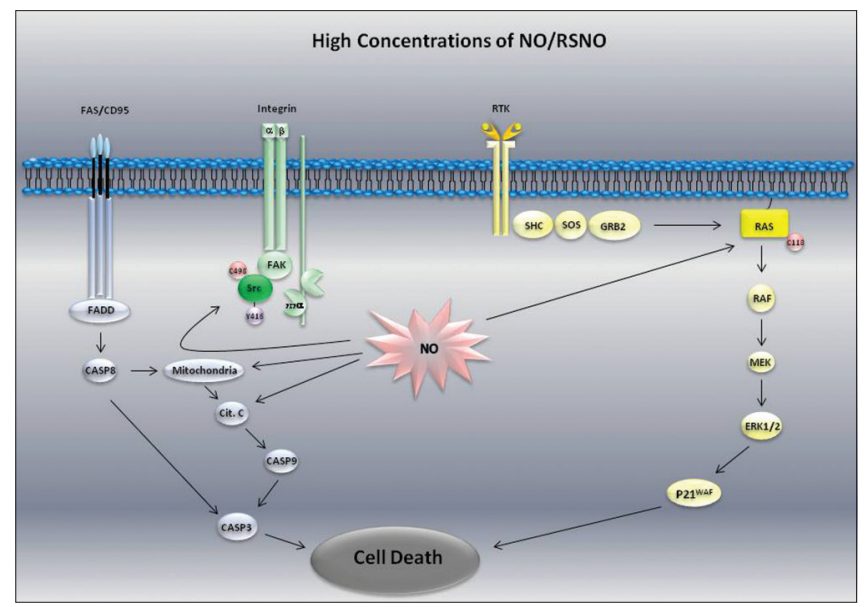

Figure 2: NO/RSNO-stimulated anti-proliferative/pro-apoptotic signaling pathways in tumor cells. that extend from seconds to days. They potentially have the capacity to stimulate apoptosis of tumor cells, inhibit metastasis, and inhibit angiogenesis. Classes of NO donors used in cancer include: Organic nitrates (glyceryl trinitrate), NONOates (DETA/NO), hybrid NO-drugs (NO-aspirin), metal-NO complexes (SNP), and RSNOs (GSNO). ${ }^{[72]}$

Metal-NO complexes and RSNOs may exert their potential anti-tumor activities through $S$-nitrosylation of intracellular proteins. In the most studied metal-NO complex, SNP, the nitrosyl moiety in the nitroprusside anion exhibits $\mathrm{NO}^{+}$character and is very reactive against thiolate anions. Upon addition of SNP to tissues, there is formation of nitrosyl-iron complexes with thiols, dinitrosyl-iron complexes, and RSNOs ${ }^{[80]}$ RSNOs are decomposed by transition metal ions, $\mathrm{Cu}^{+}$and $\mathrm{Fe}^{2+}$, and by ascorbate, through homolytic and heterolytic cleavage of the S-NO bond generating NO. In the presence of a thiol, RSNOs will react and form new RSNOs by the trans-nitrosation reaction. The newly formed RSNOs might be more reactive for structural reasons. ${ }^{[81]}$

The indiscriminate and cytotoxic systemic effects exerted in vivo by most of the NO donors have limited their use. Selective cytotoxicity in tumor cells and reduced cytotoxicity in normal cells are desirable properties for a putative chemotherapeutic NO donor.

Because of their unique characteristics related to tissue selectivity, RSNOs may prove useful in a therapeutic setting. ${ }^{[82]} \mathrm{A}$ series of RSNOs derived from $\mathrm{N}$-acetylpenicillamine and referred to as $S$-nitroso-aryl-butanamides were synthesized and characterized. ${ }^{[83]}$ The ortho- and meta-chloro derivatives of the $S$-nitroso-aryl-butanamides had a potent cytotoxic effect on MCF-7 human breast cancer cells, while human fibroblasts from normal mammary tissue maintained viability. ${ }^{[82]}$ These selective cytotoxic effects of the chloro-derivatives of $S$-nitroso-aryl-butanamides to MCF-7 human breast cancer cells are encouraging and suggest that the chloro-derivatives of the $S$-nitroso-aryl-butanamides may potentially have a chemotherapeutic effect in the treatment of human breast cancer.

\section{Conclusion}

Acting as a "double-edged sword" in tumor biology, NO plays an essential role either as an inducer of tumor progression or an inhibitor of tumor proliferation, angiogenesis, and metastasis. Cancer cells express different isoforms of NOS and generate increased levels of NO as compared to normal cells. Endogenously generated NO in tumor cells or exogenously given NO will modify the signaling proteins according to their concentrations. The oncoproteins EGFR and Src kinase can be $S$-nitrosylated and phosphorylated on tyrosine by low concentrations of NO/RSNO in tumor cells. Under the same conditions, GDP-GTP exchange on Ras was triggered by $S$-nitrosylation, resulting in cell proliferation. 
High non-physiological concentrations of NO/RSNO will promote apoptosis. The use of RSNO as cancer chemotherapeutic agents is promising. RSNOs are relatively selective in their interactions with cancer cells and promote intracellular nitrosative stress and cell death. Precise measurement of NO levels associated with the knowledge of the interactions of NO with signaling proteins in tumor cells may foster new developments in NO-based cancer chemotherapy.

\section{Acknowledgments}

The authors thank the financial support provided by the Brazilian Agency Fundação de Amparo a Pesquisa do Estado de São Paulo (FAPESP) with grant numbers 2010/19013-7 and 2012/10470-1 to HPM and 2010/51784-6 and 2013/16644-4 to AKCAR. The authors also thank Conselho Nacional de Desenvolvimento Científico e Tecnológico (CNPq) and Coordenação de Aperfeiçoamento do Ensino Superior (CAPES). PEC is a PhD fellow from FAPESP.

\section{Financial support and sponsorship}

Nil.

\section{Conflicts of interest}

There are no conflicts of interest.

\section{REFERENCES}

1. Hess DT, Matsumoto A, Kim SO, Marshall HE, Stamler JS. Protein S-nitrosylation: Purview and parameters. Nat Rev Mol Cell Biol 2005;6:150-66.

2. Iyer AK, Rojanasakul Y, Azada N. Nitrosothiol signaling and protein nitrosation in cell death. Nitric Oxide 2014;42:9-18.

3. Lim KH, Ancrile BB, Kashatus DF, Counter CM. Tumour maintenance is mediated by eNOS. Nature 2008;452:646-50.

4. Nanni S, Benvenuti V, Grasselli A, Priolo C, Aiello A, Mattiussi S, et al. Endothelial NOS, estrogen receptor b, and HIFs cooperate in the activation of a prognostic transcriptional pattern in aggressive human prostate cancer. J Clin Invest 2009;119:1093-108.

5. Yang Z, Misner B, Ji H, Poulos TL, Silverman RB, Meyskens FL, et al. Targeting nitric oxide signaling with nNOS inhibitors as a novel strategy for the therapy and prevention of human melanoma. Antiox Redox Signal 2013;19:433-47.

6. Lechner M, Lirk P, Rieder J. Inducible nitric oxide synthase (iNOS) in tumor biology: The two sides of the same coin. Semin Cancer Biol 2005;15:277-89.

7. Stuehr DJ, Nathan CF. Nitric oxide a macrophage product responsible for cytostasis and respiratory inhibition in tumor target cells. J. Exp Med 1989;169:1543-55.

8. Grimm EA, Ellerhorst J, Tang CH, Ekmekcioglu S. Constitutive intracellular production of iNOS and NO in human melanoma: Possible role in regulation of growth and resistance to apoptosis. Nitric Oxide 2008;19:133-7.

9. Feelisch M, Stamler JS. Donors of nitrogen oxides. In: Methods in
Nitric Oxide research. Feelisch M, Stamler JS, editors. Chichester, England: John Wiley; 1996. p. 71-115.

10. Siemens DR, Heaton JP, Adams MA, Kawakami J, Graham CH. Phase II study of nitric oxide donor for men with increasing prostate-specific antigen level after surgery or radiotherapy for prostate cancer. Urology 2009;74:878-83.

11. Rigas B. Novel agents for cancer prevention based on nitric oxide. Biochem Soc Trans 2007;35:1364-8.

12. Dimmeler S, Zeiher AM. Nitric oxide and apoptosis: Another paradigm for the double-edged role of nitric oxide. Nitric Oxide 1997;1:275-81.

13. Fukumura D, Kashiwagi S, Jain R. The role of nitric oxide in tumor progression. Nature 2006;6:521-34.

14. Moroz LL, Kohn AB. On the comparative biology of nitric oxide (NO) synthetic pathways: Parallel evolution of NO-mediated signaling. Adv Exp Biol 2007;1:1-44.

15. Toledo JC Jr, Augusto O. The chemical and biological properties of nitric oxide. Chem Res Toxicol 2012;25:975-89.

16. Martínez-Ruiz A, Cadenas S, Lamas S. Nitric oxide signaling: Classical, less classical, and noncassical mechanisms. Free Radic Biol Med 2011;51:17-29.

17. Murad F, Rapoport RM, Fiscus R. Role of cyclic-GMP in relaxations of vascular smooth muscle. J Cardiovasc Pharmacol 1985;7: Suppl 3:S111-8.

18. Huie RE, Padmaja S. The reaction of NO with superoxide. Free Rad Res Commun 1993;18:195-9.

19. Van der Vliet A, Eiserich J, Halliwell B, Cross CE. Formation of reactive nitrogen species during peroxidase-catalyzed oxidation of nitrite. A potential additional mechanism of nitric oxide-dependent toxicity. J Biol Chem 1997;272:7617-25.

20. Beckman J, Koppenol WH. Nitric oxide, superoxide, and peroxinitrite: The good, the bad, and the ugly. AM J Physiol 1996;271:C1424-37.

21. Carreira BP, Morte MI, Santos AI, Lourenço AS, Ambrósio AF, Carvalho CM, et al. Nitric oxide from inflammatory origin impairs neural stem cell proliferation epidermal growth factor receptor signaling. Frontiers Cell Neurosci 2014;8:343.

22. Monteiro HP. Signal transduction by protein tyrosine nitration: Competition or cooperation with tyrosine phosphorylation-dependent signaling pathways? Free Radic Biol Med 2002;33:765-73.

23. Heinrich TA, da Silva RS, Miranda KM, Switzer CH, Wink DA, Fukuto JM. Biological nitric oxide signaling: Chemistry and terminology. Br J Pharmacol 2013;169:1417-29.

24. Marino SM, Gladyshev VN. Structural analysis of cysteine s-nitrosylation: A modified acid-base motif and the emerging role of trans-nitrosylation. J Mol Biol 2010;395:844-59.

25. Monteiro HP, Arai RJ, Travassos LR. Protein tyrosine phosphorylation and protein tyrosine nitration in redox signaling. Antiox Redox Signal $2008 ; 10: 843-89$.

26. Derakhshan B, Hao G, Gross SS. Balancing reactivity against selectivity: The evolution of protein s-nitrosylation as an effector of cell signaling by nitric oxide. Cardiovasc Res 2007;75:210-9.

27. Stamler JS, Toone EJ, Lipton SA, Sucher NJ. (S) NO signals: Translocation, regulation and a consensus motif. Neuron 1997;18:691-6. 
28. Switzer CH, Glynn SA, Cheng RY, Ridnour LA, Green JE, Ambs S, et al. S-nitrosylation of EGFR and Src activates an oncogenic signaling network in human basal-like breast cancer. Mol Cancer Res 2012;10:1203-15.

29. Batista WL, Ogata FT, Curcio MF, Miguel RB, Arai RJ, Matsuo AL, et al. S-nitrosoglutathione and endothelial nitric oxide synthase-derived nitric oxide regulate compartmentalized Ras s-nitrosylation and stimulate cell proliferation. Antioxid Redox Signal 2013;18:221-38.

30. Moraes MS, Costa PE, Batista WL, Paschoalin T, Curcio MF, Borges RE, et al. Endothelium-derived nitric oxide (NO) activates the NO-epidermal growth factor receptor-mediated signaling pathway in bradykinin-stimulated angiogenesis. Arch Biochem Biophys 2014;558:14-27.

31. Curcio MF, Batista WL, Linares E, Nascimento FD, Moraes MS, Borges RE, et al. Regulatory effects of nitric oxide on Src kinase, FAK, and receptor protein tyrosine phosphatase $\alpha$ : A role for the cellular redox environment. Antiox Redox Signal 2010;13:109-25.

32. Tew KD, Mannevich Y, Grek C, Xiong Y, Uys J, Townsend DM. The role of glutathione S-transferase $P$ in signaling pathways and s-glutathionylation in cancer. Free Radic Biol Med 2011;51:299-313.

33. Gochman E, Mahajna J, Shenzer P, Dahan A, Blatt A, Elyakim R, et al. The expression of iNOS and nitrotyrosine in colitis and colon cancer in humans. Acta Histochem 2012;114:827-35.

34. Windham PF, Tinsley HN. cGMP signaling as a target for the prevention and treatment of breast cancer. Semin Cancer Biol 2015;31C:106-10

35. Seth D, Stamler JS. The SNO-proteome: Causation and classifications. Curr Opin Chem Biol 2011;15:129-36.

36. Croce CM. Oncogenes and cancer. N Engl J Med 2008;358:502-11.

37. Weinberg RA. The Biology of Cancer. Garland Science, Taylor and Francis Group; 2007. P. 844.

38. Oliveira GA, Rosa H, Reis AK, Stern A, Monteiro HP. A role for nitric oxide and for nitric oxide synthases in tumor biology. Forum Immunopathol Dis Ther 2012;3:169-82.

39. Costa PE, Batista WL, Curcio MF, Moraes MS, Borges RE, Nascimento PA, et al. Protein tyrosine phosphatase alpha regulates cell detachment and cell death profiles induced by nitric oxide donors in the A431 human carcinoma cell line. Redox Rep 2011;16:27-37.

40. Sousa MS, Latini FR, Monteiro HP, Cerutti JM. Arginase 2 and nitric oxide synthase: Pathways associated with the pathogenesis of thyroid tumors. Free Radic Biol Med 2010;49:997-1007.

41. Ridnour LA, Thomas DD, Switzer C, Flores-Santana W, Isenberg JS, Ambs S, et al. Molecular mechanisms for discrete nitric oxide levels in cancer. Nitric Oxide 2008;19:73-6.

42. Peranovich TM, da Silva AM, Fries DM, Stern A, Monteiro HP. Nitric oxide stimulates tyrosine phosphorylation in murine fibroblasts in the absence and presence of epidermal growth factor. Biochem $\mathrm{J}$ 1995;305:613-9.

43. Monteiro HP, Gruia-Gray J, Peranovich TM, Stern A. Nitric oxide stimulates tyrosine phosphorylation of focal adhesion kinase, Src kinase, and mitogen-activated protein kinases in murine fibroblasts. Free Radic Biol Med 2000;28:174-82.

44. Thibeault S, Rautureau Y, Oubaha M, Faubert D, Wilkes BC, Delisle $\mathrm{C}$, et al. S-nitrosylation of $\beta$-catenin by eNOS-derived NO promotes VEGF-induced endothelial cell permeability. Mol Cell
2010;39:468-76.

45. Dvorak HF. Vascular permeability factor/vascular endothelial growth factor: A critical cytokine in tumor angiogenesis and a potential target for diagnosis and therapy. J Clin Oncol 2002;20:4368-80.

46. Mitra SK, Schlaepfer DD. Integrin-regulated FAK-Src signaling in normal and cancer cells. Curr Opin Cell Biol 2006;18:516-23.

47. Harder KW, Moller NP, Peacock JW, Jirik FR. Protein tyrosine phosphatase $\alpha$ regulates Src family kinases and alters cell-substratum adhesion. J Biol Chem 1998;273:1890-900.

48. Franchi A, Massi D, Santucci M, Masini E, Rossi Degl'Innocenti D, Magnelli L, et al. Inducible nitric oxide synthase activity correlates with lymphangiogenesis and vascular endothelial growth factor- $\mathrm{C}$ expression in head and neck squamous cell carcinoma. J Pathol 2006;208:439-45.

49. Bani D, Masini E, Bello MG, Bigazzi M, Sacchi TB. Relaxin activates the L-arginine-nitric oxide pathway in human breast cancer. Cancer Res 1995;55:5272-5.

50. Ardini E, Agresti R, Tagliabue E, Greco M, Aiello P, Yang LT, et al. Expression of protein tyrosine phosphatase alpha (RPTP- $\alpha$ ) in human breast cancer correlates with low tumor grade, and inhibits tumor cell growth in vitro and in vivo. Oncogene 2000;19:4979-87.

51. Rahman MA, Senga T, Ito S, Hyodo T, Hasegawa H, Hamaguchi M. S-Nitrosylation at Cysteine 498 of c-Src Tyrosine Kinase Regulates Nitric Oxide-mediated Cell Invasion. J Biol Chem 2010;285:3806-14.

52. Zheng XM, Wang Y, Pallen CJ. Cell transformation and activation of pp60c-src by overexpression of a protein tyrosine phosphatase. Nature 1992;359:336-9.

53. Ahearn IM, Haigis K, Bar-Sagi D, Philips MR. regulating the regulator: Post-translational modification of RAS. Nat Rev Mol Cell Biol 2012;13:39-51

54. Casey PJ, Solski PA, Der CJ, Buss JE. P21Ras is modified by a farnesyl isoprenoid. Proc Natl Acad Sci USA 1989;86:8323-7.

55. Hancock JF, Magee AI, Childs JE, Marshall CJ. All Ras proteins are polyisoprenylated but only some are palmitoylated. Cell 1989;57:1167-77.

56. Lander HM, Ogiste JS, Pearce SF, Levi R, Novogrodsky A. Nitric oxide-stimulated guanine nucleotide exchange on p21ras. J Biol Chem 1995;270:7017-20.

57. Heo J, Campbell SL. Mechanism of p21Ras s-nitrosylation and kinetics of nitric oxide-mediated guanine nucleotide exchange. Biochemistry 2004;43:2314-22.

58. Oliveira CJR, Curcio MF, Moraes MS, Tsujita M, Travassos LR, Stern A, et al. The low molecular weight S-nitrosothiol, $\mathrm{S}$-nitroso-N-acetylpenicillamine, promotes cell cycle progression in rabbit aortic endothelial cells. Nitric Oxide 2008;18:241-55.

59. Oliveira CJR, Schindler F, Ventura AM, Moraes MS, Arai RJ, Debbas V, et al. Nitric oxide and cGMP activate the Ras-MAP kinase pathway stimulating protein tyrosine phosphorylation in rabbit aortic endothelial cells. Free Rad Biol Med 2003;35:381-96.

60. Tsujita M, Batista WL, Ogata FT, Stern A, Monteiro HP, Arai R. The nitric oxide-sensitive p21 Ras-ERK pathway mediates S-nitrosoglutathione-induced apoptosis. Biochem Biophys Res Commun 2008;369:1001-6.

61. Albanese C, Johnson J, Watanabe G, Eklund N, Vu D, Arnold A, et al Transforming p21ras mutants and c-Ets-2 activate the cyclin D1 promoter through distinguishable regions. J Biol Chem 
$1995 ; 270: 23589-97$.

62. Lavoie JN, L'Allemain G, Brunet A, Muller R, Pouyssegur J. Cyclin D1 expression is regulated positively by the p42/p44MAPK and negatively by the p38/HOGMAPK pathway. J Biol Chem 1996;271:20608-16.

63. Huang L, Carney J, Cardona DM, Counter CM. Decreased tumorigenesis in mice with a KRas point mutation at C118. Nat Commun 2014;5:5410.

64. Arai RJ, Masutani H, Yodoi J, Debbas V, Laurindo FR, Stern A, et al. Nitric oxide induces thioredoxin-1 nuclear translocation: Possible association with the p21Ras survival pathway. Biochem Biophys Res Commun 2006;348:1254-60.

65. Ogata FT, Batista WL, Sartori A, Gesteira TF, Masutani H, Arai RJ, et al. Nitrosative/oxidative stress conditions regulate Thioredoxin-interacting protein (TXNIP) expression and Thioredoxin-1 (TRX-1) nuclear localization. Plos One 2013;8:e84588.

66. Zhu X, Huang C, Peng B. Overexpression of thioredoxin system proteins predicts poor prognosis in patients with squamous cell carcinoma of the tongue. Oral Oncol 2011;47:609-14.

67. Arai RJ, Ogata FT, Batista WL, Masutani H, Yodoi J, Debbas $\mathrm{V}$, et al. Thioredoxin-1 promotes survival in cells exposed to s-nitrosoglutathione: Correlation with reduction of intracellular levels of nitrosothiols and up-regulation of the ERK1/2 MAP kinases. Toxicol Appl Pharmacol 2008;233:227-37.

68. Masaki S, Masutani H, Yoshihara E, Yodoi J. Deficiency of thioredoxin-binding protein-2 (TBP-2) enhances TGF-b signaling and promotes epithelial to mesenchimal transition. Plos One 2012;7:e39900.

69. Shan W, Zhong W, Zhao R, Oberley TD. Thioredoxin 1 as subcellular biomarker of redox imbalance in human prostate cancer progression. Free Radic Biol Med 2010;49:2078-87.

70. Pacher P, Beckman JS, Liaudet L. Nitric Oxide and peroxynitrite in health and disease. Phisiol Rev 2007;87:315-424.

71. Martindale JL, Holbrook NJ. Cellular response to oxidative stress: Signaling for suicide and survival. J Cell Physiol 2002;192:1-15.

72. Bonavida B, Baritaki S, Huerta-Yepez S, Vega MI, Chaterjee D, Yeung K. Novel therapeutic applications of nitric oxide donors in cancer: Roles in chemo- and immunosensitization to apoptosis and inhibition of metastases. Nitric Oxide 2008;19:152-7.

73. Muir CP, Adams MA, Graham CH. Nitric oxide attenuates resistance to doxorubicin in three-dimensional aggregates of human breast carcinoma cells. Breast Cancer Res Treat 2006;96:169-76.

74. Huerta-Yepez S, Baritaki S, Baay-Guzman G, Hernandez-Luna MA, Hernandez-Cueto A, Vega MI, et al. Contribution of either YY1 or BclXL-induced inhibition by the NO-donor DETANONOate in the reversal of drug resistance, both in vitro and in vivo. YY1 and BclXL are overexpressed in prostate cancer. Nitric Oxide 2013;29:17-24.

75. Sen N, Hara MR, Kornberg MD, Cascio MB, Bae BI, Shahani $\mathrm{N}$, et al. Nitric oxide-induced nuclear GAPDH activates p300/CBP and mediates apoptosis. Nat Cell Biol 2008;10:866-73.

76. Ali AA, Coulter JA, Ogle CH, Migaud MM, Hirst DG, Robson $\mathrm{T}$, et al. The contribution of $\mathrm{N}_{2} \mathrm{O}_{3}$ to the cytotoxicity of the nitric oxide donor DETA/NO: An emerging role for S-nitrosylation. Biosci Rep 2013;33:pii: e00031.

77. Radomski MW, Palmer RM, Moncada S. An L-arginine/nitric oxide pathway present in human platelets regulates aggregation. Proc Natl Acad Sci USA 1990;87:5193-7.

78. Monteiro HP, Silva EF, Stern A. Nitric oxide: A potential inducer of adhesion-related apoptosis-anoikis. Nitric Oxide 2004;10:1-10.

79. Meloche S, Pouyssegur J. The ERK1/2 mitogen-activated protein kinase pathway as a master regulator of the G1-to $\mathrm{S}$ phase transition. Oncogene 2007;26:3227-34

80. Rochelle LG, Kruszyna H, Kruszyna R, Barchowsky A, Wilcox DE, Smith RP. Bioactivation of nitroprusside by porcine endothelial cells. Toxicol Appl Pharmacol 1994;28:123-8.

81. Wang PG, Xian M, Tang X, Wu X, Wen Z, Cai T, et al. Nitric oxide donors: Chemical activities and biological applications. Chem Rev 2002;102:1091-134

82. Monteiro HP, Sartori A, Reis AKCAR. Differential loss of cell viability after exposure of MCF-7 breast cancer cells and normal human mammary fibroblasts to s-nitroso-arylamides. Abstracts of Papers ACS 2013;246:138-MED.

83. Santana RG, Paiva DR, Gomes RS, Reis AKCA. ${ }^{1} \mathrm{H}$ and ${ }^{13} \mathrm{C}$ NMR analysis of 2-acetamido-3-mercapto-3methyl-N-aryl-butanamide and 2-acetamido-3-methyl-3-nitrososulfanyl-N-aryl-butanamide derivatives. Magn Reson Chem 2013;51:316-9.Dae nos dolorrorerum fugitat estiundes et amus ut que vel maximilibusa qui to et rerestiis

This is an open access article distributed under the terms of the Creative Commons Attribution-NonCommercial-ShareAlike 3.0 License, which allows others to remix, tweak, and build upon the work non-commercially, as long as the author is credited and the new creations are licensed under the identical terms.

For reprints contact: reprints@medknow.com 